\title{
Numerical Investigation and Fatigue Life Estimation of Conventional and Modified Piston of Diesel Engine
}

\author{
Hiregoudar Yerrennagoudaru and Manjunatha K.
}

\begin{abstract}
Nowadays engine components are subjected to higher load at elevated temperature than before, due to the increase requirement regarding weight, performance and exhaust gas emission. Thus, Fatigue due to simultaneous thermal and cyclic loading become determinant among the damage forms. At the same time, there is the need to reduce development time and cost to handle the growing number of model variant. Therefore, the development of suitable simulation tools, which reduces the number of necessary component tests, seems to be very rewarding. By using special material (aluminum alloy) we can reduce the fatigue load (Thermal and cyclic) on the piston by using finite element analysis, ANSYS work bench 14.5 version.
\end{abstract}

Index Terms-Diesel engine, fatigue life, conventional piston, modified piston.

\section{INTRODUCTION}

Mechanical systems are frequently subjected to cyclic or random loading, inducing damages and fatigue failure of many structural components. One of these structures, namely pressure vessels, is widely used in many important branches of industry, such as power engineering, chemical engineering, and the petrochemical industry.

IC engine, in general, are loaded by cyclic pulses and as a result stress concentration zones with plastic strains may appear which induce initiation and propagation of fatigue cracks, leading to fatigue failure. Thus, it is obligatory to estimate the fatigue limit and the fatigue life of pressure vessels to ensure safe service time for these important expensive structures having far-reaching effects after their failure.

IC engine Piston are subjected to operating loading conditions which includes pressure, nozzle loads and thermal loads, resulting in the occurrence of stress concentration zones, initiation and propagation of fatigue cracks. Approaches to fatigue life prediction are based on intensity stresses and strains. In the present calculation, fatigue evaluation is carried out using stress based approach.

Approach and Assumptions:

- ANSYS Meshing is used for meshing the component.

- ANSYS 14.5 is used for solving and post-processing.

- Material is assumed to be linear and isotropic.

- Stress based approach is used for fatigue evaluation.

Manuscript received March 10, 2015; revised January 12, 2016

The authors are with the Mechanical Engineering Department, RYMEC Bellary, Karnataka, India (e-mail: hiregoudar.yng@gmail.com, manju.btl@gmail.com).
- $\quad$ Fatigue life prediction is done as per ASME VIII DIV 2.

\section{LITERATURE REVIEW}

Y. Takenaka [1] in this study the intake flow is calculated for the steady state and transient condition. Semin, Rosli Abu Bakar [2] The result of the intake and exhaust flow simulation in an engine cylinder shows that the simulation commences at bottom dead centre (BDC) and continues for a time interval corresponding to 7200 of crank revolution. F. Pavri, J. Benajes, X. Margot, A.Gil [3] in the main study, the flow characteristics inside the engine cylinder equipped with different piston configurations were compared. A. D. Gosman, P. S. Harvey [4] analyzed fuel-air mixing and combustion in an ax symmetric direct injection diesel engine numerically. Benny Paul1 [5] reported a study on the effect of helical, spiral, and helical-spiral combination manifold configuration on air motion and turbulence inside the cylinder of a Direct Injection (DI) diesel engine motored at $3000 \mathrm{rpm}$. F. Payri [6] studied Three-dimensional flow calculations of the intake and compression stroke of a four-valve direct-injection Diesel engine have been carried out with different combustion chambers.

\section{METHODOLOGY}

Geometries can be created top-down or bottom-up. Top-down refers to an approach where the computational domain is created by performing logical operations on primitive shapes such as Piston crown, Skirt of the Piston and Piston bowl. Bottom-up refers to an approach where one first creates vertices (points), connects those to form edges (lines), connects the edges to create faces, and combines the faces to create volumes. Geometries can be created using the same pre-processor software that is used to create the grid, or created using other programs (e.g. CAD, UNI-GRAPHICS).

A. Conventional Piston and Modified Piston (see Table I)

TABLE I: THE MATERIAL PROPERTIES

\begin{tabular}{ll}
\hline \hline Material Type & Aluminum Alloy \\
\hline Young's Modulus $(\mathrm{GPa})$ & 70 \\
Poisson's Ratio & 0.3 \\
Density $(\mathrm{Kg} / \mathrm{m} 3)$ & 2770 \\
Thermal Exp.cm $/ \mathrm{cm}^{\circ} \mathrm{C}$ & $23.4 \times 10^{-6}$ \\
Thermal Conductivity $(\mathrm{W} / \mathrm{mK})$ & 155 \\
Yield Stress $(\mathrm{MPa})$ & 240 \\
\hline \hline
\end{tabular}

\section{B. Boundary Condition of Conventional Piston}

The connecting rod support of IC is constrained in all 
translational DOF as given in Fig. 1.

C. Loading Conditions for Both Conventional Piston and Modified Piston

1) Temperature load

- Piston exposed to min temperature $=25^{\circ} \mathrm{C}$

- Vessel exposed maximum temperature $=6500 \mathrm{C}$

2) Pressure load

- Vessel exposed maximum Pressure $=60 \mathrm{Bar}$

- Vessel Exposed minimum pressure $=1$ bar

D. Results and Discussion of Conventional Piston (see Fig. 2-4)

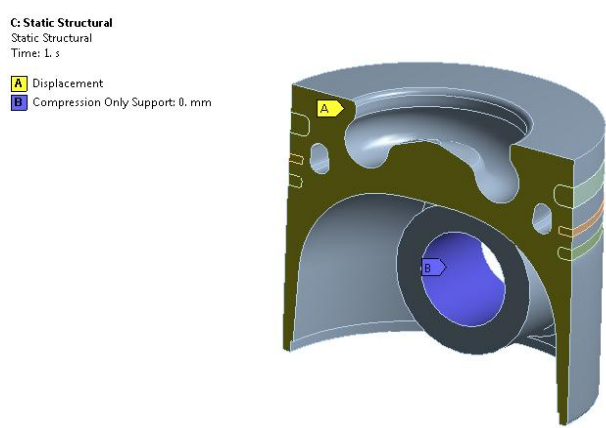

Fig. 1. Boundary conditions.

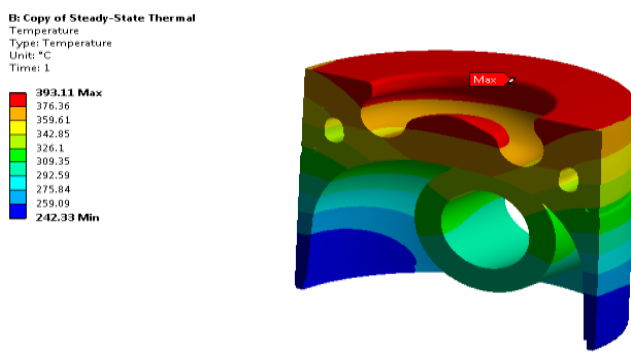

Fig. 2. Temperature contour.

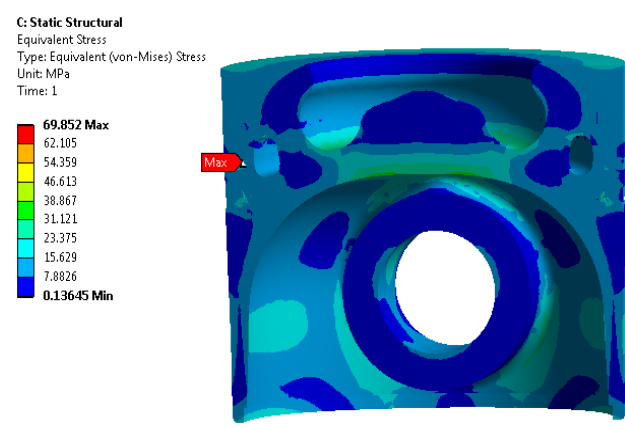

Fig. 3. Von-misses plot.

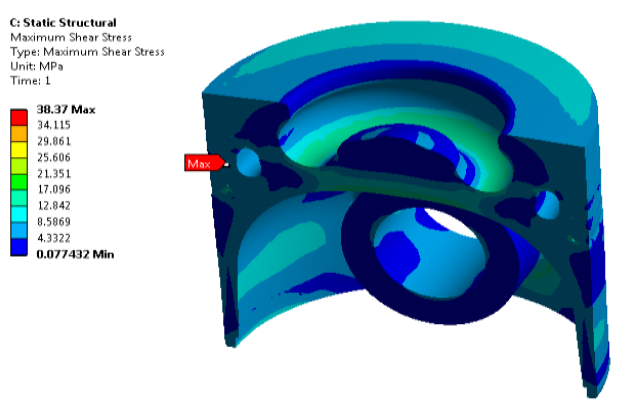

Fig. 4. Shear stress plot.

\section{E. Boundary Condition of Modified Piston}

The connecting rod support of IC is constrained in all translational DOF as given in Fig. 5.

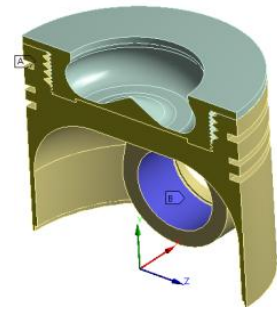

Fig. 5. Boundary conditions.

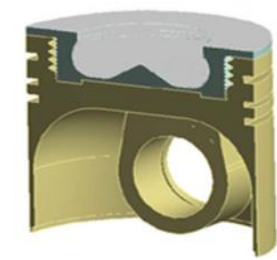

Fig. 7. Modified piston with coating

Platinum-300microns.

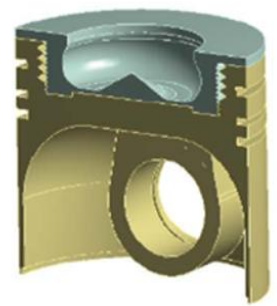

Fig. 6. Modified piston without coating.

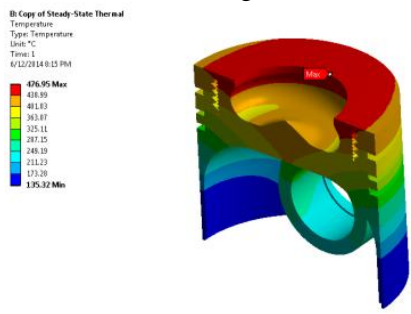

Fig. 8. Temperature contour
F. Modified Piston without Coating and Modified Piston with Platinum Coating (see Figs. 6-7)

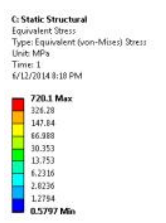

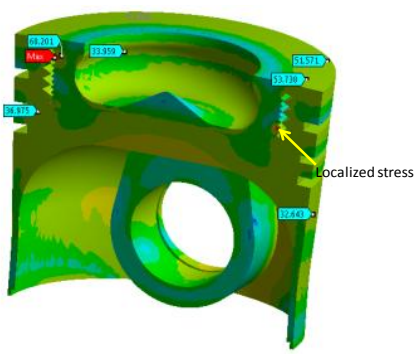

Fig. 9. Von-misses plot.
G. Results and Discussion of Modified Piston (see Figs. 8-14)

Fig. 12 shows the variation of Swirl Ratio (SR) inside the cylinder with respect to crank angle for piston configurations at $1500 \mathrm{rpm}$. During the suction stroke, the swirl ratio increases till the maximum valve lift position and gradually decreases till the end of valve closing and again increases at the end of compression stroke. In the comparison of swirl ratio at $1000 \mathrm{rpm}$, maximum value is obtained for PISTON-2 configuration over the other two manifolds.

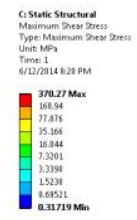

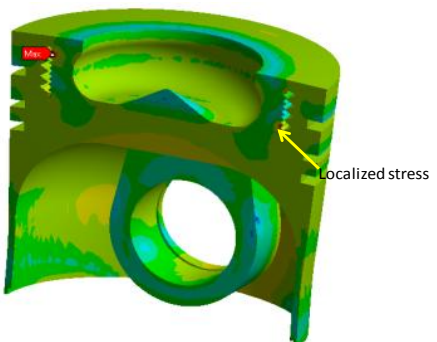

Fig. 10. Shear stress plot.

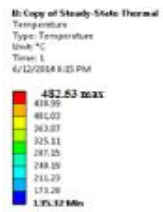

Fig. 11. Modified Piston with platinum coating. 


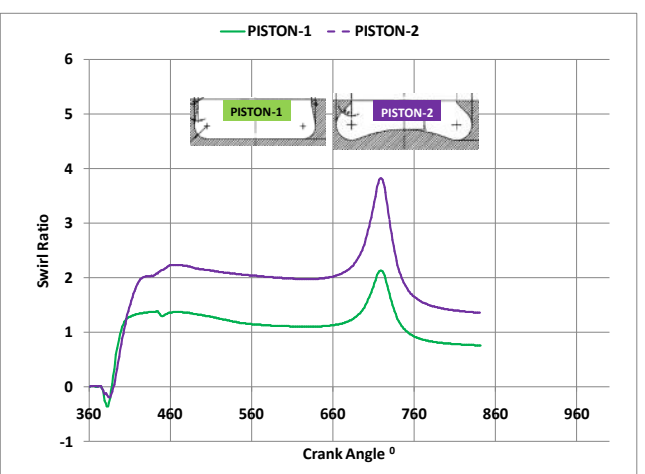

Fig. 12. Swirl ratio.

Fig. 13 and Fig. 14 shows the variation of the TR with CADs at $1500 \mathrm{rpm}$ engine speed considered in this study during suction and compression strokes. It is observed that the TR ratio changes its magnitude (positive to negative or vice versa) indicating overall air movement changes its direction during entire cycle with CADs. The reasons for this could be: (i) change in the overall tumble flow pattern due to low pressure and bifurcation zones, (ii) change in piston speed with CA, and (iii) change in the direction of the piston movement during suction and compression strokes. With an increase in engine speed, variation in TR is marginal at all the CA. However, at 720 CAD, TR is maximum.

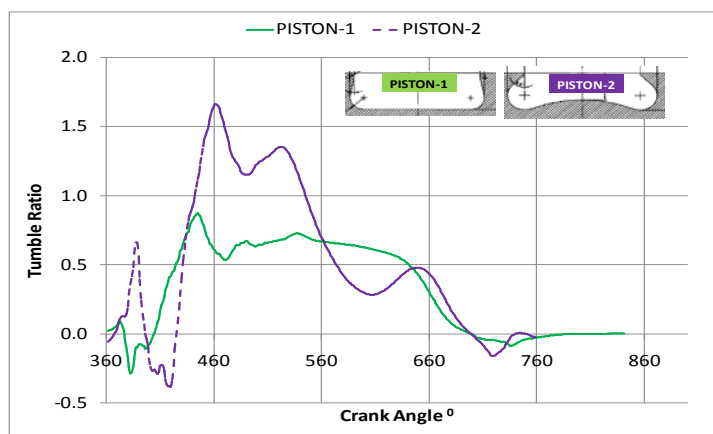

Fig 13. Tumble ratio Y.

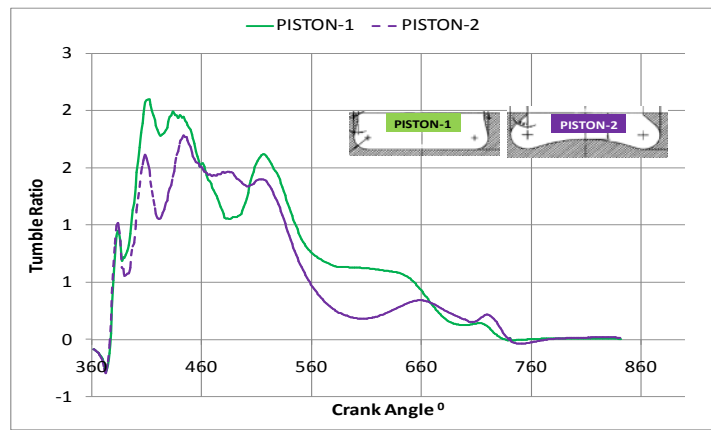

Fig. 14. Cross tumble ratio.

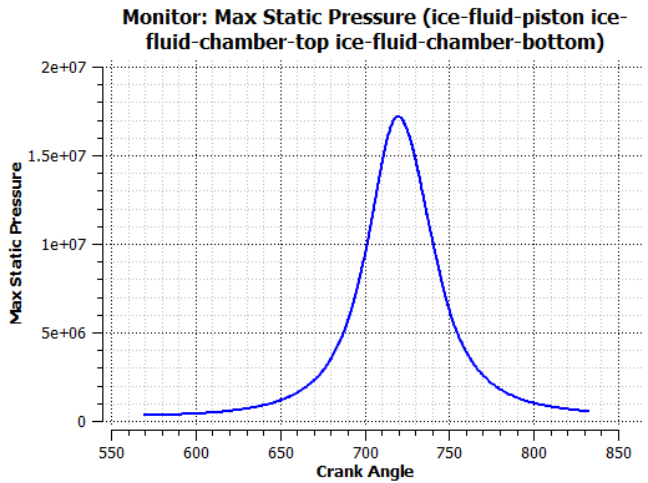

Fig. 15. Pressure Vs crank angle.

\section{H. Results and Discussion}

The in-cylinder fluid dynamics in engines has been shown to play an important role during the combustion process. In particular, in-cylinder fluid flows contribute to fuel air mixing which is important to the fuel-burning rate. Turbulence generated in an I.C. engine is anisotropic. During the Intake process, the flow passing the valve separates and results in a highly unsteady motion. This flow contains both large-scale and small-scale turbulence. Since turbulence has a major effect on combustion, flow-mixing and on heat-transfer in an engine, to model the flow inside an engine a proper turbulence model should be used. In this analysis RNG k epsilon model is used. The intake manifold and piston bowl design is one of the most important factors that affect the air/fuel mixing and the subsequent combustion and pollutant formation processes in a direct injection diesel engine. The bowl geometry and dimensions, such as the pip region, the bowl lip area and the torus radius, are all known to have an effect on the in-cylinder mixing and combustion process. In order to understand better the effect of the pip region, three piston bowls with different pip designs but with the same lip area and torus radius were designed and investigated using computational fluid dynamics (CFD) engine modeling. A commercial CFD was used to model the in-cylinder flows and without combustion process.

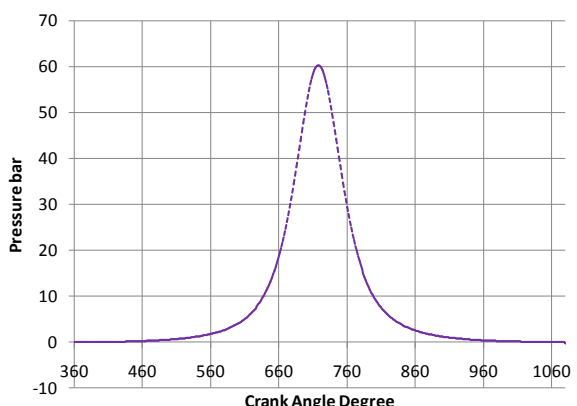

Fig. 16. Pressure Vs crank angle.

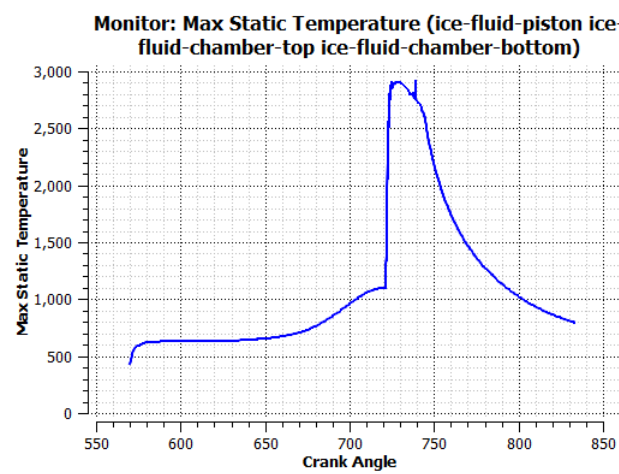

Fig. 17. Temperature Vs CA.

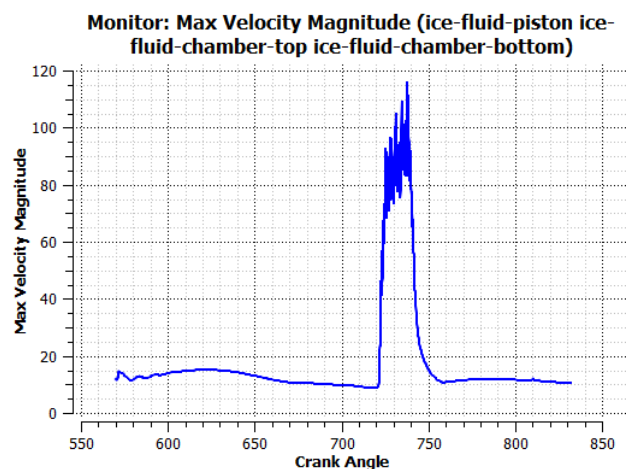

Fig. 18a. Maximum Velocity Vs CA. 
Monitor: Mass-Average Turbulent Kinetic Energy (k) (icefluid-piston ice-fluid-chamber-top ice-fluid-chamberbottom)

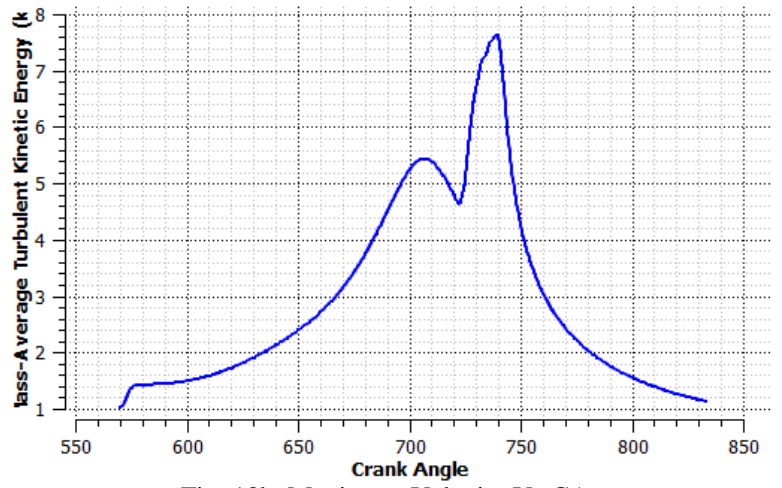

Fig. 18b. Maximum Velocity Vs CA.

The moving mesh is generated by DYNAMIC MESH ROUTINE, a moving mesh module in FLUENT. In engine operation, valves and the piston move, so the mesh should move according to the real engine in order to simulate the charge of valve and piston position with crank angle. Piston and piston bowl movement are decided by the stroke, connecting rod and crank angle. Calculation starts at $360^{\circ} \mathrm{CA}$ and ends at $1080^{\circ} \mathrm{CA}$. A cold flow analysis is performed for this purpose. Cold flow simulations for IC engines can provide valuable design information to engineers. These simulations allow for the effect on volume efficiency and/or swirl and tumble characteristics to be predicted based on changes in port and combustion chamber design, valve lift timing, or other parameters.

\section{Swirl and Tumble Ratio inside the Cylinder}

Swirl and tumble ratios are generally defined as the ratio of the angular momentum of the in cylinder flow about each of the three orthogonal axes. It is normalized against the same gas rotating as solid body the same axes at crank speed. The usual method for determining these ratio is, first the center of the combustion chamber is determined. Then the $\mathrm{X}, \mathrm{Y}$ and $\mathrm{Z}$ are dined with the origin of the center of the mass. The $\mathrm{Z}$ axis is defined as being parallel to the line of piston motion. The $Y$ axis is defined as perpendicular to $\mathrm{Z}$ and parallel to central axis of the inlet manifold. Finally, the $X$ axis is defined as perpendicular to $\mathrm{Z}$ and $\mathrm{Y}$.

It shows Stronger the tumble motion (more TR), more the turbulent kinetic energy released during its break down at the end of compression stroke. Also, it helps in higher turbulence levels at the time of ignition.

\section{CONCLUSION}

- In-cylinder calculations of the intake and compression strokes of a DI Diesel engine equipped with two intake valves were carried out. The resulting flow field was analyzed for different combustion chamber shapes using CFD software Fluent.

- During the intake stroke the shape of the piston bowl does not play any significant role. In this area, the maximum swirl and turbulence velocity values are obtained at the maximum valve lift.

- By Fatigue analysis of modified piston we will drawn the following points

- Fatigue life of conventional piston approximately 868587 Cycles.

- Fatigue life of modified piston approximately 868590 Cycles.

- $83.62^{\circ} \mathrm{C}$ temperature difference which will help to burn any Fuel which has very low cetane.

- The life of the modified piston is better than the conventional one.

- Thermal stress of the modified piston is lower than the conventional piston.

- By using platinum coating on piston crown temperature distribution will be more compared to without coating, it will help to burn any fuel which is having low cetane value.

\section{REFERENCES}

[1] Y. Takenaka, M. Yabe, Y. Aoyagi, and T. Shiozaki, "Three dimensional computation of in-cylinder flow with intake port in DI diesel engine," Dokumentation Kraftfahrtwesen e. V, 1990.

[2] S. R. A. Bakar and A. R. Ismail, "Computational visualization and simulation of diesel engines valve lift performance using CFD,' American Journal of Applied Sciences, vol. 5, no. 5, pp. 532-539, 2008.

[3] F. Pavri, J. Benajes, X. Margot, and A. Gil, "CFD modeling of the in-cylinder flow in direct-injection diesel engines," Computers \& Fluids, vol. 33, no. 8, pp. 995-1021, September 2004.

[4] A. D. Gosman and P. S. Harvey, "Computer analysis of fuel-air mixing in an axisymmetric D. I. diesel," SAE Transactions, pp. 121-141, 1982

[5] B. Paul and V. Ganesan, "Flow field development in a direct injection diesel engine with different manifolds," International Journal of Engineering, Science and Technology, vol. 2, no. 1, 2010.

[6] F. Payri, J. Benajes, X. Margot, and A. Gil, "CFD modeling of the in-cylinder flow in direct-injection diesel engines," Computers \& Fluids, vol. 33, no. 8, pp. 995-1021, 2004.

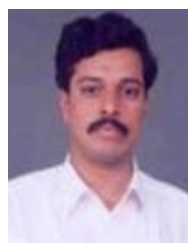

Hiregoudar Yerrennagoudaru is currently a professor at the Department of Mechanical Engineering, RYMEC, Bellary. He obtained his M.Tech from Gulabarga University and Ph.D degree under JNTU, Anatapur. He has teached the IC engines, heat transfer, power plant and other thermal subjects for UG and PG students and has over 30 years of teaching experience. He has presented several research papers at the international and national conferences till the date.

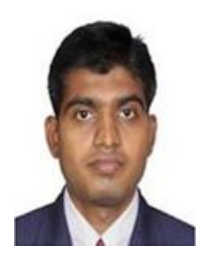

Manjunatha K. is currently an Assistant Professor with the Mechanical Department at RYMEC, Bellary. He obtained his B.E in mechanical and M.Tech in thermal power engg. from VTU, BELGAUM and pursuing his Ph.D degree under VTU, Belgaum. He has been teaching the basic and applied thermodynamics and other thermal subjects for UG and PG students. He has 11 years' teaching experience in total. His current research interest includes IC Engines and Heat Transfer. He has presented several research papers at the international and national journals till the date. 